\title{
Retinopathy of Prematurity (ROP): Current Understanding and Management
}

\author{
M AMANNAN ${ }^{1}$, SADEKA CHOUDHURY MONI ${ }^{2}$, MOHAMMOD SHAHIDULLAH $^{3}$
}

\begin{abstract}
Introduction:
Retinopathy of prematurity (ROP) is a major cause of blindness in children .It is a vascular disease of the eye unique to preterm infants characterized by failure of retinal blood vessels to grow and develop normally. It results in severe visual impairment and blindness in newborns ${ }^{1-3}$. Originally it was called retrolental fibroplasias (RLF), named for the end-stage of the disease in which a white, vascularized plaque could be seen behind the lens in an eye that was often completely blind.
\end{abstract}

A baby developing blindness in early days of life, can never regain vision and will have no perception of light of this colourful world, Therefore he or she has to bear this lifetime visual disability as a long lasting scar of premature birth.

\section{Epidemiology:}

ROP remains one of the leading causes of blindness in children in the United States and developedworld. All preterm babies are at high risk for ROP, and very low birth weight is additional risk factor.

The epidemiology, natural history, and pathogenesis of ROP over a period of 15 years have been demonstrated in the largest study of the Multicenter Trial of Cryotherapy for Retinopathy of Prematurity (CRYOROP) ${ }^{4-8}$. In that study, the reported incidence of ROP among infants $<1250 \mathrm{~g}$ was $65.8 \%$. Approximately $6 \%$ of low birth weight infants ( 1251 g) develop severe ROP that requires treatment to prevent visual los. ${ }^{5}$. However,subsequent studies conducted during the past 15 years on the incidence of ROP have shown differing results, some indicating a decrease in the incidence of ROP and others suggesting no change ${ }^{9-12}$. Since the time CRYOROP study, there are advances in neonatal care, decreases in mortality rates and generation of knowledge that

1. Professor, Department of Neonatology, BSMMU, Dhaka

2. Assistant Professor, Department of Neonatology, BSMMU, Dhaka

3. Professor and Chairman, Department of Neonatology, BSMMU, Dhaka

Correspondence: Dr M A Mannan, Mobile :01715055506, E-mail: drmannan64@gmail.com several systemic diseases other than prematurity affect ROP.Therefofore incidence and severity of ROP showed variation. Numerous ophthalmic and nonophthalmic prognostic factors have been identified to be associated with increased risk of unfavorable ROP outcome $5,6,8$.

For the developing world ROP is an emerging problem. In India in a prospective cohort of 552 preterm low birth weight newborns in a tertiary care hospital with or without risk factors, incidence of ROP was $22.3 \%$ and at 3 year follow up of those treated with laser photocoagulation, $9 \%$ were found blind due to retinal detachment ${ }^{13}$. In Bangladesh reported incidence of ROP based on targeted screening program is not available. Follow up eye examination of preterm infants $<33$ weeks enrolled in another study demonstrated the incidence as $4.4 \%{ }^{14}$.

\section{Risk factors for ROP:}

ROP is essentially a disease of prematurity. Other documented risk factors for ROP includes Cardiorespiratory instability, prolonged oxygen therapy,repeated episodes of apnoea of prematurity, anemia needing blood transfusion, neonatal sepsis etc. Risk is higher when the baby is severely ill 15 .

\section{History:}

The First ROP case was described by Terry in 1942 in an infant who had grey, blood vessel-covered membranes behind the pupil. After that report, an epidemic of blindness occurred in the 1950s and 1960s among the survived tiny newborns in the United States. During that time high doses of oxygen was being used to treat apnoea of prematurity without monitoring. Uncontrolled supplemental oxygen was thought to be one of the causative factors of this devastating disease process. Attempts were made to curtail use of essential oxygen in the premature nursery. ROP did decrease but at the expense of increased mortality and higher incidence of cerebral palsy. With the advent of pulse oxymetry in 1970s, and beyond, oxygen therapy became controlled and it was thought that ROP would disappear. Unfortunately this proved to be untrue.With the advancement of neonatal services, 
sicker babies continued to survive and ROP again rose to frightingly high level. Therefore small gestational age and very low birth weight correlated more strongly with occurrence of ROP than did oxygen administration. The new ROP epidemic brought the ophthalmologists and the retinologists together to find out an effective treatment of this devastating disorder related to prematurity. The first step was to develop a common nomenclature followed by natural history study and subsequently a treatment protocol.

Retinal Vascular development: (Fig-1,2)
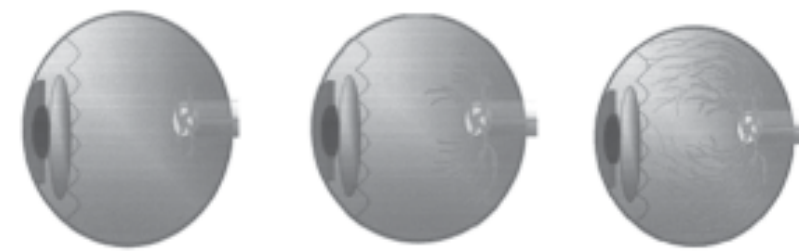

Fig.-1: Vessels migrate from disc towards ora serrata at 16 weejs

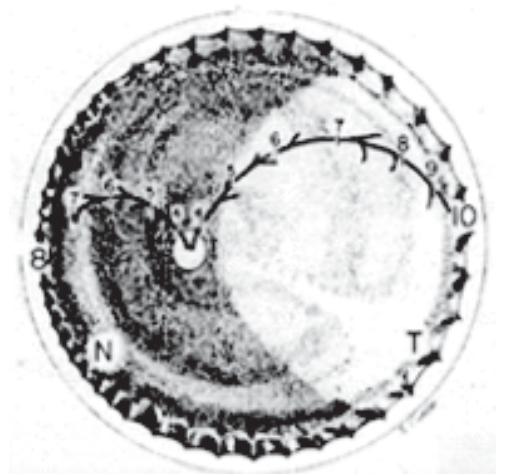

Fig.-2: Vessels extend to nasal ora at 36 weeks and temporal ora at 39-41 weejs

\section{Retina has two sources of blood supply.}

Hyloid artery, a major branch of primitive dorsal ophthalmic artery which is blood vessel destined to supply the human retina enters the globe at the gestational age of 6 weeks and grows forward proceeding outward and toward the ora serrata and it is the $16^{\text {th }}$ weeks of gestation retina's blood supply is completely established.

Before completion of 16 weeks choroidal vessels alone nourish both outer and inner retina.

Growth is symmetric from the optic disc and reaches the nasal ora serrata at about 35 to 40 weeks' gestation and the temporal ora at about 38 to 44 weeks' gestation (Fig.-2). Therefore, the retinas of infants born prematurely are incompletely vascularized, with a peripheral avascular zone, the area of which depends on the gestational age.

\section{Pathogenesis of ROP:}

Arrest of retinal vascular growth:

The first phase of ROP in premature infants consists of cessation of the normal retinal vascular growth .

\section{Vascular proliferation:}

As the infant matures, the resulting non-vascularized retina becomes increasingly metabolically active and increasingly hypoxic. The second phase of ROP, retinal neovascularization, is hypoxia induced. Vascular endothelial growth factor (VEGF) typifies these factors, and there is the striking increase in messenger RNA for VEGF-in the avascular retina compared with the vascularized-retina in the kitten model of oxygen-induced retinopathy. These findings have been confirmed in a human-infant's eye. IGF-1, another angiogenic growth factor is critical to normal vascular development and low IGF-1 predicts ROP ${ }^{16}$.

The delicate growing retinal capillaries of a preterm infant are subjected to many injurious changes resulting from prolonged (days) hyperoxia and other stresses such as intraventricular hemorrhage, pneumothorax, hypovolemic shock, and sepsis as confirmed in animal models. Animal models suggest that such injuries result in severe pruning back of the growing vessels. There follows a variable pause in vascular growth, then at approximately 30 to 34 weeks' gestation (in the human), the vessels begin to grow again, but with an abnormal "catch-up" pattern that involves excessive numbers of vessels, impaired capillary progress, and sometimes vascular escape from the retina into the vitreous. Vessel regrowth (neovascularization) is the visible ROP that ophthalmologists see. It is likely that excessive tissue hypoxia leads to overproduction of growth factors and, thus, excessive new vessel growt typifies these factors.

The International Classification of ROP (ICROP) Upto 1980 the prevailing old classification of RLF based on direct ophthalmologic findings did not describe the progression of ROP, its severity, or points in its course at which to attempt interventions. It was impossible to design an interventional clinical trial because enrollment criteria could not be specified. In 1983 international committee, comprised of 23 ophthalmologists from 11 different countries finalized the new classification at the National Eye Institute. Thus in 1984, the International Classification of ROP (ICROP) was developed ${ }^{17}$. The Committee for the Classification of Retinopathy of Prematurity, comprised of 23 ophthalmologists from 11 different countries, The ICROP characterizes ROP by its position (zone), severity (stage), and extent (clock hours); and delineates whether the "plus disease" component is present. 
Table-I Classification of ROP (Table-I, Fig-3,4,5) ICROP 18

\section{Table-I}

International Classification- ROP) ICROP

Classification of ROP(ICROP)

\begin{tabular}{lll}
\hline Location Zone 1 & Circle with optic nerve at it's centre and a radius of twice the distance from \\
optic nerve to macula
\end{tabular}

Zone 2 Concentric circle from edge of Zone 1 to ora serrata nasally and equator temporally

Zone 3 Lateral crescent from Zone 2 to ora serrata temporally

Severity Stage 1 Presence of thin white demarcation line seperating vascular from avascular retina

Stage 2 Addition of depth and width to the demarcation line separating vascular from avascular retina

Stage 3 Presence of extraretinal fibrovas cular proliferation with abnormal vessels and fibrous tissue extendting from ridge to vitreous

Stage 4 Partial retinal detachment not involving macula (4A) and involving macula (4B)

Stage 5 Complete retinal detachment

Plus disease Presence of dilation and tortuosity of retinal vessels at posterior pole of eye. Also associoated with papillary rigidity and vitreous haze

Extent Extent of ROP described in $30^{\circ}$ clock hours ( a total of 12 clock hours of $30^{\circ}$ each)

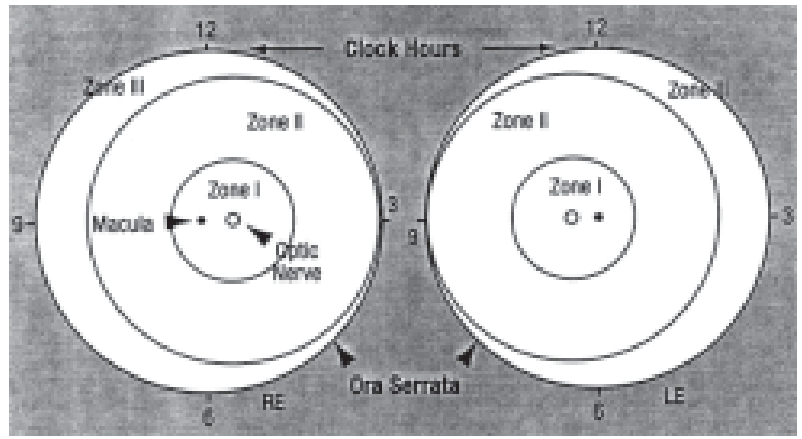

Fig.-3
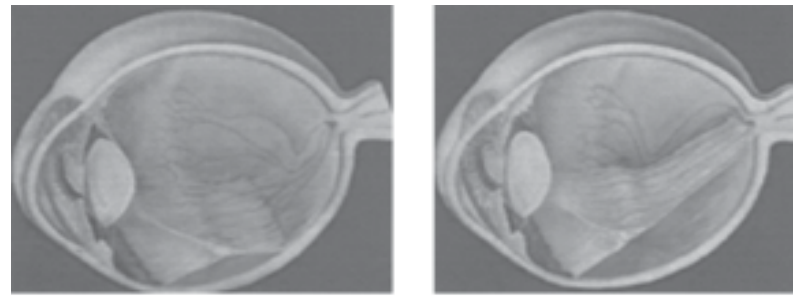

4A: extrafoveal RD

4B: RD including the fovea

Stage-5: Total retinal detachment (RD)

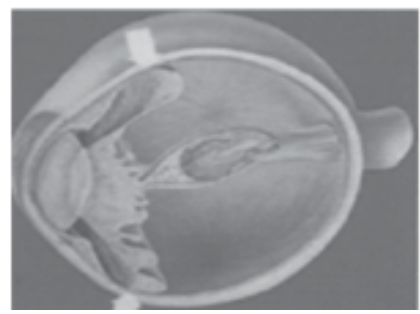

Fig.-5

\section{Staging of ROP}

Stage-1: a faint demarcation line

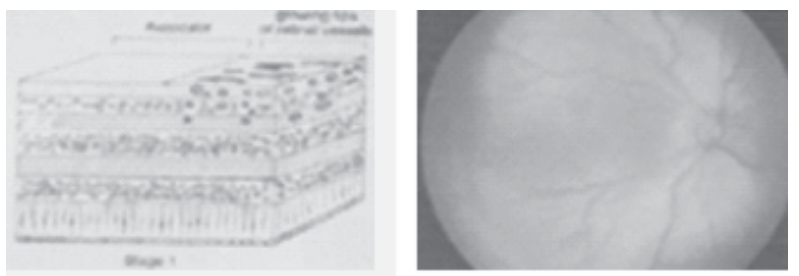

Stage-2: An elevated ridge

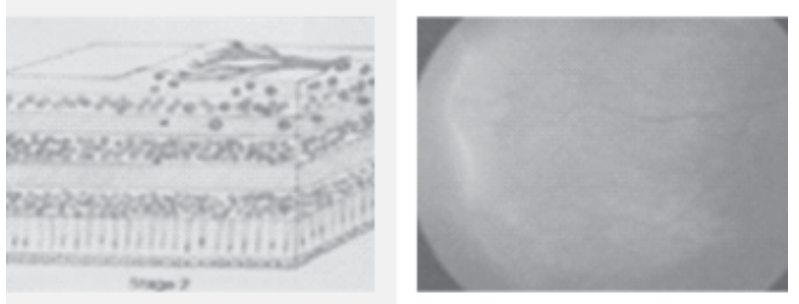

Stage-3: Extraretinal fibrovascular tissue
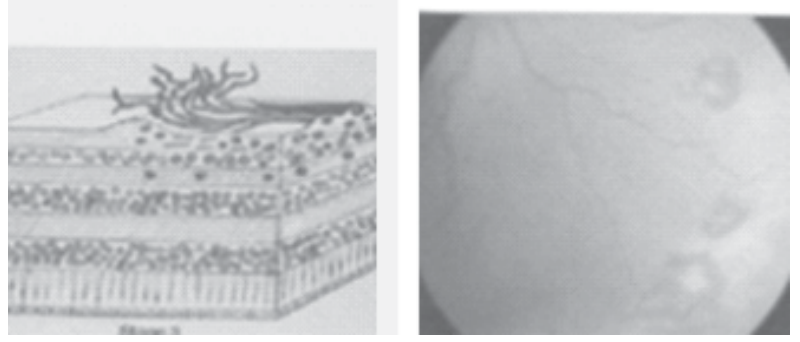

Stage 4: (A\&B): sub-total retinal detachment (RD)

Fig.-4 


\section{Composite Categories of ROP:}

In the clinical trial to test the efficacy of cryotherapy to prevent vision loss from ROP, two composite definitions of certain degrees of ROP severity were developed. These are Threshhold ROP , Prethreshhold ROP, Aggressive Posterior ROP (APROP) . Initially developed as research tools, they proved extremely useful and are commonly used in practice today.

"Threshold ROP" is defined as the presence of ROP in either zone I or zone II, at least 5 continuous right eye) or 8 composite (left eye) clock hours of stage 3 , and plus disease. Untreated threshold ROP progresses to retinal detachment in approximately $50 \%$ of cases.

"Prethreshold ROP" is less severe and is used as a marker to identify infants who require more frequent ROP examinations to discern threshold ROP as soon as it occurs. Any ROP (less than threshold) in zone I is considered prethreshold. In zone 2, stage 2 ROP with plus disease or stage 3 without plus disease is prethreshold. Zone II, stage 3+ ROP without enough clock hours to meet threshold criteria also is considered prethreshold.

Aggressive Posterior ROP (AP-ROP): A rapidly progressing, severe form of ROP, if untreated progresses rapidly to stage $5 \mathrm{ROP}$. The characteristics features of this type of ROP includes it's posterior location, prominence of plus disease, and the illdefined nature of the retinopathy. Observed most commonly in Zone 1, it may also occur in posterior Zone II.

"No ROP" is a category with potential disaster if it is erroneously interpreted to mean that the retina is mature and no longer at risk for developing ROP. "No ROP" is an incomplete description; it always must be followed by zone of the immature retinal vessels or notation that the retina is fully vascularized (mature).

\section{Screening of ROP:}

Reliable and evidence- based screening protocol is necessary for ensuring appropriate standard of care for ROP. But the screening program should be consistent, clinically effective, safe, cost effective and must avoid extraneous /unnecessary examination of these tiny newborns. Therefore, some practical issues must be addressed by ROP screening guidelines.

\section{Whom to screen:}

Selecting neonates for screening depends on risk of ROP at different gestation. Gestation and birth weight cut-off for screening shifts lower as the quality of care improves. Therefore the target population for screening in a country should be based incidence risk factors reported in that country.

Current recommendation for a screening eye examination is for all infants born at less than or equal to 32 weeks gestation, and/or weighing less than $1500 \mathrm{~g}$ at birth. This is to ensure that all infants at significant potential risk are screened. In the past, an examination also was recommended for any infant who received oxygen for 48 hours or more regardless of gestational age and birth weight, but that has been changed. For larger, older babies, it is left to the neonatologists' discretion to determine which other infants have sufficient risk factors to warrant an eye examination.

\section{Timing of screening:}

Several published guidelines are available for ROP screening ${ }^{19-21}$. The initial eye examination should be conducted by 32 weeks' postmenstrual age or 4 weeks' chronological age whichever comes later ${ }^{22}$.

The rationale for this change comes from data that show that $90 \%$ of eyes that reach threshold do so between 33.6 and 42 weeks after conception. The mean age at which infants required treatment in the ET-ROP trial (EARLY TREATMENT ROP TRIAL)was 35 plus or minus 2 weeks after conception ${ }^{23}$.

\section{Frequency of Screening (Table-II):}

Follow up is based on retinal findings which are classified according to Internattional Classification of ROP (ICROP). The follow up schedule is as follows : 24

Table-II

Follow-up of screening

\begin{tabular}{|c|c|c|}
\hline $\begin{array}{l}\text { Zone of } \\
\text { retinal } \\
\text { findings }\end{array}$ & $\begin{array}{l}\text { Stage of retinal } \\
\text { findings }\end{array}$ & $\begin{array}{l}\text { Follow up } \\
\text { interval }\end{array}$ \\
\hline \multirow[t]{3}{*}{ Zone 1} & Immature vascularization & 1-2 weeks \\
\hline & Stage 1 or 2 & 1 week or less \\
\hline & Regressing ROP & 1-2 weeks \\
\hline \multirow[t]{5}{*}{ Zone 2} & Immature vascularization & 2-3 weeks \\
\hline & Stage 1 & 2 weeks \\
\hline & Stage 2 & 1-2 weeks \\
\hline & Stage 3 & 1 week or less \\
\hline & Regressing ROP & 1-2 weeks \\
\hline \multirow[t]{2}{*}{ Zone 3} & Stage 1 or 2 & 2-3 weeks \\
\hline & Regressing ROP & 2-3 weeks \\
\hline
\end{tabular}


4. Termination of Screening: $\mathbf{2 4 , 2 5}$

Criteria to stop further examination:

- Full retinal vascularization; this usually occurs at about 40 th weeks of postmenstrual age and mostly completed by the $45^{\text {th }}$ weeks ${ }^{26}$.

- Regression of ROP noted

\section{Who should screen:}

ROP examinations should be "performed by an ophthalmologist trained in indirect ophthalmoscopy with sufficient knowledge and experience to enable accurate identification of the location and sequential retinal changes of ROP" 27 .

Other recommended personnel for screening examination are:

- Retina subspecialist

- General ophthalmologist trained in indirect ophthalmoscopy

- Trained neonatologist/ Pediatrician

- Trained Technician/ Nurses

\section{Methods of screening}

1.Indirect ophthalmoscopy: Examination of the retina is performed using the binocular indirect ophthalmoscope (a head-mounted scope with light source) and a lens for focusing.

2. Use of RetCam and telemedicine Screening of ROP (Fig-6) :

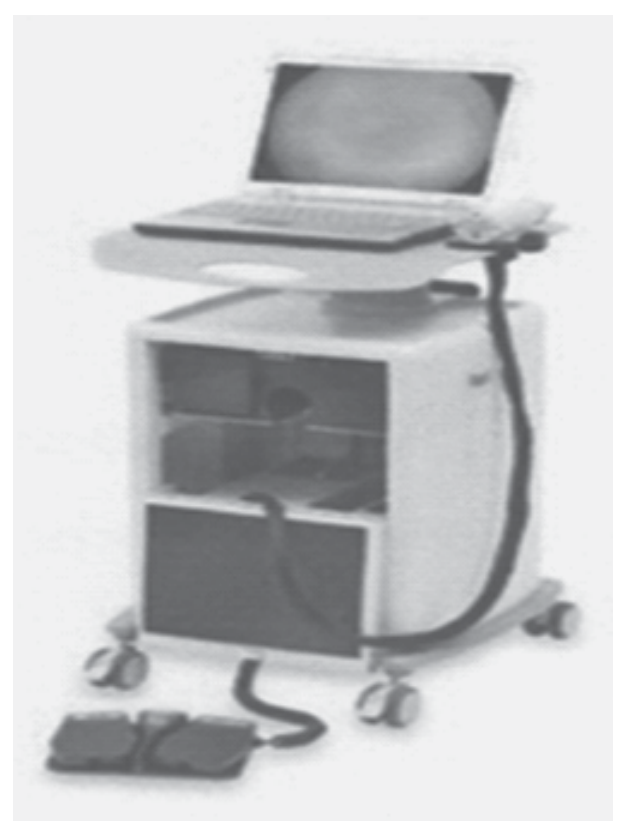

Fig.-6
The RetCam is a camera used to photograph the retina of infants. Use of digital wide-field retinal imaging RetCam is welldescribed for ROP screening ${ }^{28}$. This camera do not require a dilated pupil or contact with the eye. Retinal images taken by the camera can be stored, transmitted to expert, reviewed, analyzed and sequentially compared over time and are useful for telemedicine purposes. The advantages of this method are that fewer screening ophthalmologists would be needed, making it ideal for more remote or rural areas.

\section{Place of Screening:}

The ideal setting for screening is under a radiant warmer in the NICU, under the guidance of neonatologist. Discharged and stable babies may be screened in the trained ophthalmologist's clinic or in the NICU.

\section{Treatment of ROP:}

Treatment of ROP consists of destroying the portion of the retina that is unvascularized in order to preserve the rest of it. The rationale for why this works is thought to be that the avascular retina is a source of growth factors that promote abnormal neovascularization. When the avascular retina is destroyed, the release of growth factors ceases, and neovascularization involutes and regresses. Vascular endothelial growth factor (VEGF) and other growth factors, both known and unknown, are thought to play a role. Timely recognition of the disease is important because of the short window of opportunity during which treatment is effective ${ }^{29}$.

\section{Indication of ROP treatment:}

ET-ROP Recommendations for treatment: (Table-III) ${ }^{23}$

Table-III

ET-ROP Recommendations for treatment

\begin{tabular}{llll}
\hline Zone 1 & No Plus & Stage1 & Follow \\
& & Stage2 & Follow \\
& & Stage3 & Treat \\
& Plus & Stage1 & Treat \\
& & Stage2 & Treat \\
Zone 2 & \multirow{2}{*}{ No Plus } & Stage3 & Treat \\
& & Stage1 & Follow \\
& & Stage2 & Follow \\
& \multirow{2}{*}{ Plus } & Stage3 & Follow \\
& & Stage1 & Follow \\
& & Stage2 & Treat \\
& & Stage3 & Treat \\
\hline
\end{tabular}


2. Treatment modalities before retinal detachment:

Retinal cryotherapy and laser photocoagulation have both proven to be successful methods of treating active ROP. They are used to ablate the avascular retina anterior to the fibrovascular ridge.

i. Cryotherapy: Cryotherapy was the mode of treatment in the absence of portable laser machines. In the late 1960s xenon arc photocoagulation and transscleral cryotherapy were used for the treatment of acute ROP ${ }^{30}$. The Multicentre Trial of Cryotherapy for Retinopathy of Prematurity (CRYO-ROP) for the first time established the beneficial effect of cryoablation of the peripheral avascular retina ${ }^{31}$. It usually requires a general anaesthetic or sedation and ventilation. Cryotherapy is a painful and inflammatory procedure. Adverse effects include conjunctivitis, eyelid swelling, hypotony (dangerously low pressure in the eye), infection, laceration and haemorrhage of conjunctiva, preretinal and vitreous haemorrhage.glaucoma.

ii. Laser Photocoagulation: Head-mounted lasers rapidly became an attractive alternative to cryotherapy 32. The procedure can be done more often in the NICU without general anesthesia.. Indirect laser photocoagulation is more convenient and technically easier to administer and is of particular advantage over cryotherapy in treatment of posterior disease. It permits a precise and relatively atraumatic delivery of treatment with less ocular and systemic adverse effects The complications reported with laser are cornea, iris and lens burns, hyphaema, retinal haemorrhages and choroidal rupture.

A comparison of laser photocoagulation with cryotherapy for threshold ROP at 10 years has suggested better structural and functional outcome for eyes undergoing laser ${ }^{33}$.

3. Treatment modalities after retinal detachment:

In some eyes, despite treatment or before treatment can be done, a retinal detachment occurs. Retinal detachments (RDs) despite timely and thorough ablation which usually have poor anatomic and visual prognosis ${ }^{34,35}$.

Although several operations to treat such cases have been described, there is no

randomized prospective data to guide management. The various procedures described are open-sky vitrectomy, ${ }^{36,37}$ scleral buckling procedures (SBPs),
38,39 closed vitrectomy and lensectomy with or without SBPs ${ }^{40,41}$. The success rate for surgery to reattach the retina in infants with ROP is poor as there is rapid degeneration of the photoreceptor cells after retinal detachment ${ }^{42}$.

\section{Other Modalities of Treatment:}

Anti-VEGF therapies: VEGF is important in the development of ROP and new therapies using inhibitors of VEGF for treating ROP are being developed to block retinal neovascularisation. Various anti-VEGF treatments ( bevacizumab) have been used in a small number of patients either by intra vitreal injection or injection into anterior chamber of the eye. These have yet to be fully evaluated.

\section{Gene therapy}

Another method of producing local, ocular anti-VEGF therapy has used gene transfer via an intra vitreal injection of a control vector carrying the appropriate gene. This treatment has been reported as showing good results in animal testing but has yet to be used in humans.

Long-term Sequelae Of Retinopathy Of Prematurity:

The most serious long term-sequela of ROP is blindness and this devastating disability affects mobility, education, developmental milestones, social interactions etc. In blind children who have no light perception have free-running circadian rhythms hildren remains wakeful at night and sleeps at day time causing havoc in family and school. For this reason, even in cases in which it is apparent that little vision can be saved, at least maintenance of light perception is attempted.

Serious long term consequences can occur in children with severe $\mathrm{ROP}$ requiring treatment. Mild to moderate degree of peripherl vision loss (about $6.2 \%$ reduction) has been observed in the lasered versus unlasered eyes ${ }^{43}$.

Despite protecting against the acute blindness of active ROP, eyes that required laser often have areas of traction or thinned retina that put them at increased risk of retinal detachment at older ages. Between 10 and 15 years of age, new retinal folds or detachments developed in $4.5 \%$ of the threshold eyes treated with cryotherapy, and $7.7 \%$ of threshold eyes not treated in the original CRYO-ROP cohort followed for 15 years ${ }^{44}$. Frequent eye examinations are mandatory throughout life in all patients who had serious ROP in infancy. 
Other longterm sequelae as reported with follow up of infants with ROP mplicationsincludes co requiring vitrectomy, cataract, amblyopia (loss of vision caused by disuse of one eye, often caused by a difference between the two eyes ), strabismus, early presenting myopia of high degree etc ${ }^{45}$.

\section{ROP Screening In Bangladesh:}

Neonatal health has achieved significant progress in Bangladesh which has fostered the attainment of Mellinium Development Goals in due time. Neonatal health services have been extended throughout the country and due to improved neonatal services, increased numbers of pretem low birth weight babies are surviving. Therefore, ROP is an emerging problem. Although the magnitude of the problem has not been assessed in large scale, ROP screening has already been initiated. Some enthusiastic pediatric ophthalmologist with cooperation from neonatologist started to screen the tiny infants for ROP under their own initiative. Currently Neonatologists and ophthalmologist have come forward to conduct ROP screening in large scale in some reptuted eye institutes and several Government and non-Government institutes with support from international organizations.

\section{Conclusion and Recommendation:}

ROP is essentially a disease of prematurity. Despite good efforts to control the risks of premature birth and improvement of prenatal care, premature birth cannot be avoided. But blindness and/or visual disability due to ROP is largely preventable. Timely identification through ROP screening and proper intervention in due time are the mainstay of preventing this devastating disability.

Furthermore, while caring these tiny newborns, controlled oxygen exposure should be ensured.

Finally raising awareness about this long lasting scar of premature birth among neonatologists, ophthalmologists and above all,among parents should not be under-estimated.

\section{References:}

1. Hunter DG, Mukai S. Retinopathy of prematurity: pathogenesis, diagnosis and treatment. Int Ophthalmol Clin 1992;32:163-84.

2. Gibson DL, Sheps SB, Uh SH, Schechter MT, McCormick AQ. Retinopathy of prematurityinduced blindness: birth weightspecific survival and the new epidemic. Pediatrics 1990;86: 405-12.

3. Biglan AW, Brown DR, Macpherson TA. Update on retinopathy of prematurity. Semin Peratlo 1986;10:187- 95.

4. Cryotherapy for Retinopathy of Prematurity Cooperative Group. Multicenter trial of cryotherapy for retinopathy of prematurity: preliminary results. Arch Ophthalmol. 1988;106:471-79.

5. Palmer EA, Flynn JT, Hardy RJ, Metz HS, Flynn JT et al. Incidence and early course of retinopathy of prematurity. Ophthalmology. 1991;98: 1628-40.

6. Schaffer DB, Palmer EA, Plotsky DF, Metz HS, Flynn JT, t et al, on behalf of The Cryotherapy for Retinopathy of Prematurity Cooperative Group. Prognostic factors in the natural course of retinopathy of prematurity. Ophthalmology. 1993;100:230-237.

7. Sears J, Capone A. Retinopathy of prematurity. In: Yanoff M, Duker JS, eds. Ophthalmology. London, United Kingdom: Mosby International Ltd; 1999:8.19.1-8.19.8.

8. Cryotherapy for Retinopathy of Prematurity Cooperative Group. The natural ocular outcome of premature birth and retinopathy. Status at 1 year. Arch Ophthalmol. 1994;112:903-12.

9. Allegaert K, De Coen K, Devlieger H, EpiBel Study Group. Threshold retinopathy at threshold of viability: the EpiBel study. $\mathrm{Br} \mathrm{J}$ Ophthalmol. 2004;88:239-42.

10. Bullard SR, Donahue SP, Feman SS, Sinatra RB, Walsh WF. The decreasing incidence and severity of retinopathy of prematurity. JAAPOS. 1999;3:46-52.

11. Hussain N, Clive J, Bhandari V. Current incidence of retinopathy of prematurity, 1989-1997. Pediatrics. 1999;104(3) : e26.

12. Blair BM, O'Halloran HS, Pauly TH, Stevens JL. Decreased incidence of retinopathy of prematurity, 1995-1997. J AAPOS. 2001;5: 118-22

13. Chaudhari S, Patwardhan V, Umesh Vaidya, Kadam $S$ and Kamat A.Retinopathy of Prematurity in a Tertiary Care Center-Incidence, 
Risk Factors and Outcome. Indian Pediatr 2009; 46:2109-224.

14. Ahmed AS, Muslima $\mathrm{H}$, Anwar KS, Khan NZ, Chowdhury MA, et al. Retinopathy of prematurity in Bangladeshi neonates. J Trop Pediatr. 2008; 54(5):333-39.

15. Maheshwari R, Kumar H, Paul VK, Singh M, Deorari AK, et al. Incidence and risk factors of retinopathy of prematurityin a tertiary care newborn unitin New Delhi.Natl Med J India 1996;9: 211-14.

16. LEH Smith. Pathogenesis of retinopathy of prematurity. Acta Paediatr 2002; 91 ( Suppl s437) : 26- 28.

17. Committee for Classification of Retinopathy of Prematurity. An international classification of retinopathy of prematurity. Arch Ophthalmol 1984;102:1130-34.

18. The International Classification of Retinopathy of Prematurity revisited. Arch Ophthalmol 2005; 1213:991-99.

19. Royal College of Ophthalmologists and British Association of Perinatal Medicine. Retinopathy of prematurity: guidelines for screening and treatment : Report of a joint working party: Early Hum Dev. 1996;46:239-58.

20. Joint statement of the American Academy of Pediatrics, The American Association for Pediatric Ophthalmology, and Strabismus and the American Academy of Ophthalmology: Screening examination of premature infants for retinopathy of prematurity. Pediatrics. 2001; 108:809- 11.

21: Canadian Association of pediatric Ophthalmologists adhoc Committee; Guidelines for screening examinations of retinopathy of prematurity. Can J Ophthalmol.2000; 35:251-52.

22. Screening examination of premature infants for retinopathy of prematur ity.Pediatrics 2006; 117:572-76.

23. Early Treatment for Retinopathy of Prematurity Cooperative Group. Revised indications for the treatment of retinopathy of prematurity. Results of early treatment of retinopathy of prematurity randomized trial. Arch Ophthalmol 2003; 121:1684-94.
24. American Academy of Pediatrics, Section on Ophthalmology, Screening examination of premature infantsfor retinopathy of prematurity. Pediatrics; 117:572-76.

25. Jalali S, R anand, H kumar, Dorgra MR, Azad EV, Gopal I. Programme planning and screening strategy in retinopathy of prematurity. Indian J Ophthalmol 2003; 51: 89-97.

26. Quiram PA, Capone A,. Current understanding and management of retinopathy of prematurity. Current opinion in Ophthalmology , 2007, 18: 228-34.

27. Section on Ophthalmology AAP, AAO, AAPOS. Policy statement: screening examination of premature infants for retinopathy of prematurity. Pediatrics 2006;117:572-76.

28. Athikarisamy SE, Patole S, Lam GC, Dunstan $\mathrm{C}$ and Rao S. Screening for retinopathy of prematurity (ROP) using wide-angle digital retinal photography by non-ophthalmologists: a systematic review 2014. $\mathrm{Br} \mathrm{J}$ Ophthalmol. 2014. pii: bjophthalmol-2014-304984. doi: 10.1136/bjophthalmol-2014-304984.

29. Fielder AR. Cryotherapy of retinopathy of prematurity. In: Davidson SI, Jay B, editors. Recent advances in ophthalmology, vol. 8. Edinburgh: Churchill Livingstone; 1992. p. 12948.

30. Palmer EA, Biglan AW, Hardy RJ. Retinal ablative therapy for active retinopathy of prematurity: history, current status and prospects. In: Silverman WA, Flynn JT, editors. Contemporary issues in fetal medicine and neurology, vol. 2. Retinopathy of prematurity. Oxford: Blackwell Scientific; 1985. p. 207-28.

31. Cryotherapy for Retinopathy of Prematurity Cooperative Group. Multicentre trial for cryotherapy for retinopathy of prematurity: preliminary results. Arch Ophthalmol 1988;106:471-79.

32. Capone A Jr, Diaz-Rohena R, Sternberg P Jr, Mandell B, Lambert HM, et al. Diode-laser photocoagulation for zone I threshold retinopathy of prematurity. Am J Ophthalmol 1993; 116(4): 444-50.

33. Ng EYJ, Connolly BP, McNamara A, Regillo C, Vander JF, Tasmad W. A comparison of laser 
photocoagulation with cryotherapy for threshold retinopathy of prematurity at 10 years. Part 1. Visualfunction and structural outcome. Ophthalmology 2002;109: 928-35.

34. Cryotherapy for Retinopathy of Prematurity Cooperative Group. Multicentre trial for cryotherapy for retinopathy of prematurity: ophthalmological outcome at 10 years. ArchOphthalmol 2001;119:110-18.

35. Gilbert W, Quinn GE, Dobson V, et al. Multicentre trial of cryotherapy for retinopathy cooperative group. Partial retinal detachment at 3 months after threshold retinopathy of prematurity. Long-term structural and functional outcome. Arch Ophthalmol 1996;114:1085-91.

36. Tasman W, Borrone RN, Bolling J. Open sky vitrectomy for total retinal detachment for retinopathy of prematurity. Ophthalmology 1987;94:449-52.

37. Hirose T, Katsumi O, Mehta MC, Schepens CL. Vision in stage 5 retinopathy of prematurity after retinal reattachment by opensky vitrectomy. Arch Ophthalmol 1993;111:345-49.

38. McPherson A, Hittner HM. Scleral buckling in 2 1/2- to 11-monthold premature infants with retinal detachments associated with acute retrolental fibroplasias. Ophthalmology 1979;86:819-36.

39. Grunwald E, Yassur Y, Ben-Sira I. Buckling procedures for retinal detachment caused by retrolental fibroplasias in premature babies. $\mathrm{Br} \mathrm{J}$ Ophthalmol 1980;64: 98-101.
40. Machemer R. Closed vitrectomy for severe retrolental fibroplasias in the infant. Ophthalmology 1983;90:436-41.

41. Zilis JD, deJuan E, MAchemer R. Advanced retinopathy of prematurity and visual results of vitreous surgery. Ophthalmology 1990;97: 821-26.

42. Quinn GE, Dobson V, Barr CC, Davis BR, Flynn $\mathrm{JT}$, et al. Visual acuity in infants after vitrectomy for severe retinopathy of prematurity. Ophthalmology 1991;98(7): 5-13.

43. Quinn GE, Dobson V, Hardy RJ, Tung B, Phelps $\mathrm{DL}$, et al. Visual fields measured with double arc perimetry in eyes with threshold retinopathy of prematurity from the cryotherapy for retinopathy of prematurity trial. The CRYO-ROP Cooperative Group. Ophthalmology 1996;103(9): 1432-27.

44. 15-year outcomes following threshold retinopathy of prematurity: final results from the multicenter trial of cryotherapy for retinopathy of prematurity: Cryotherapy for Retinopathy of Prematurity Cooperative Group. Arch Opthalmol 2005; 123(3): 311- 18.

45. Repka MX, Summers CG, Palmer EA, Dobson $\mathrm{V}$, TUng $\mathrm{B}$, et al. The incidence of ophthalmological interventions in children with birth weights less than 1251 grams: results through 5.5 years. Ophthalmology 1998; 105:1621-27. 